\title{
Método alternativo para a determinação do limite de contração a partir de pastilha parafinada em um Argissolo Vermelho Distrófico Arêníco
}

\section{Alternative method for determining the shrinkage limit in a paraffined tablet in a Red Distrophic Arenic Argisail}

\author{
Rômulo Augusto Aragones Aita* \\ Ronaldo Facco** \\ Arthur Piccolo Werlang*** \\ Mauro Kumpfer Werlang ${ }^{* * * *}$
}

Resumo:

O limite entre os estados semi-sólido e sólido numa amostra de solo é o limite de contração. A umidade que determina o limite inferior da zona de friabilidade do solo é obtida a partir da determinação do limite de contração. Para essa determinação, a metodologia clássica utiliza mercúrio. Esse metal pode acarretar efeitos adversos, tanto para o meio ambiente como para a saúde humana. Nesse sentido, o método da pastilha parafinada pode constituir-se numa alternativa para a determinação do limite de contração sem a necessidade do uso de mercúrio. Assim, o objetivo deste estudo foi a determinação e a comparação dos resultados obtidos para o limite de contração com a utilização de mercúrio e, sem o uso de mercúrio, mas com a utilização de parafina. Utilizaram-se quatro amostras de solo de um Argissolo Vermelho Distrófico arênico respectivamente aos horizontes diagnósticos A, E e Bt. Os valores dos limites de contração foram obtidos utilizando-se o método deslocamento de mercúrio e o método da pastilha parafinada, com oito repetições para cada amostra. Os resultados obtidos para os limites de contração determinados utilizando-se as duas metodologias mostraram baixos valores de desvio-padrão. O teste de hipóteses para amostras independentes mostrou que não houve variação significativa a um valor-p de 0,20 . Adotando-se o nível de significância a partir de $10 \%$ entre os valores do limite de contração determinado pelo método proposto pela MB-55 (ABNT, 1948) e o método com a pastilha parafinada, para os horizontes diagnósticos em análise, as médias diferiram.

\section{Abstract:}

The boundary between the solid and semi-solid states in a soil sample is the shrinkage limit. The moisture that determines the lower limit of the friability zone of the soil is obtained from the determination of the shrinkage limit. For this determination, the tratitional methodology uses mercury. This methal may have adverse effects both for the environment and for human health. Thus, the method of paraffined tablet may constitute an alternative to determinate the shrinkage limit without the necessity of using mercury. The aim of this study is to determine and compare the obtained results for the shrinkage limit with the use of mercury and without the use of mercury, but using paraffin. It was used four samples of soil from a Red Distrophic Arenic Argisoil, respectively from horizonts A, E and $\mathrm{Bt}$. The values of the shrinkage limit were obtained using the mercury displacement method and the paraffined tablet method, eight times for each sample. The results of the shrinkage limit determinated using both methods showed up low values of standart deviation. The hypothesis test for independent samples showed no significant variation to a p-value of 0.20 . Adopting the significance level from $10 \%$ between the values of the shrinkage limit determined from the proposed method from MB-55 (ABNT, 1948) and the paraffined tablet method, for the analised horizonts, the means differ.
* Graduado em Agronomia pela Universidade Federal de Santa Maria (UFSM). Mestrando em Geografia na UFSM.

** Graduado em Geografia pela UFSM. Mestrando em Geografia na mesma universidade.

*** Graduado em Engenharia Civil pela UFSM.

**** Doutor em Ciência do Solo pela UFSM. Professor associado no Departamento de Geociências da UFSM.

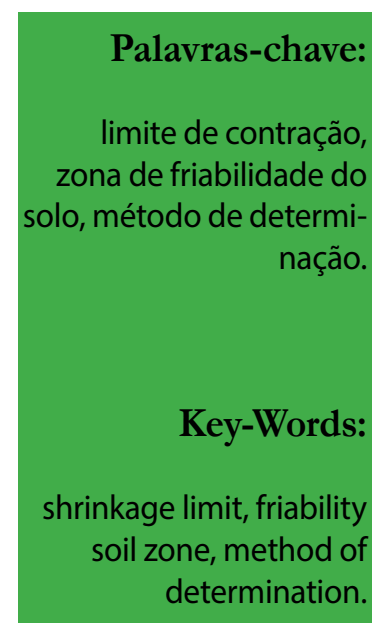




\section{INTRODUÇÃO}

$\Delta$ Iguns problemas ambientais relacionados Aaos solos, que já perduram algumas décadas, instigaram e ainda hoje incentivam a realização de pesquisas e a proposição de novas metodologias de estudo do solo. A intensa mobilização do solo, associada à mecanização excessiva e preparo do solo em condições de umidade inadequadas, vêm causando alterações no arranjamento entre as partículas do solo. Estas alterações afetam principalmente as propriedades físicas, tendo como conseqüência, a perda das condições favoráveis ao desenvolvimento de plantas.

A adoção de técnicas convencionais de manejo em ambientes propensos ao desequilíbrio, pode alterar substancialmente os processos dinâmicos do solo (ABRAHÃO et al., 1998). Operações de manejo que envolve a excessiva mobilização do solo causam alterações no arranjamento das partículas, o tornado susceptível à compactação. Segundo Silva et al. (1986), a determinação da faixa de friabilidade para cada solo é necessária quando se deseja a conservação do solo e execução de operações agrícolas com o mínimo gasto de energia.

Quando um solo tem umidade muito elevada, apresenta-se como um fluido denso, isto é, no estado líquido. À medida que a água evapora, ele se endurece e, para certo teor de umidade, ele perde sua capacidade de fluir, porém poderá ser moldado e conservar a sua forma. Este teor de umidade é o limite de liquidez, e o solo encontra-se no estado plástico. A água continuará a evaporar até o estado plástico desaparecer e o solo se desmanchará ao ser trabalhado. Este é o estado semi-sólido, isto é, o limite de plasticidade. Continuando-se a secagem, o solo atingirá, gradualmente, o estado sólido.

A definição clássica para a consistência foi proposta por Russel; Russel (1950), citado por Baver et al., (1973), onde classifica em primeiro lugar a manifestação da forças físicas como o comportamento da gravidade, pressão, empuxo e tração no solo; em segundo a tendência do solo a aderir-se a corpos estranhos e, por fim, a sensação de tato nos dedos do observador. Nesse sentido, as formas de consistência são consideradas como dura, quando o solo está seco, friável, quando o solo encontra-se em estado úmido e, pegajosa quando o solo está saturado. Portanto, acontecem transições progressivas de um estado seco para úmido, depois para molhado e, então, saturado. Parte-se de uma consistência dura e quebradiça, para uma consistência friável, passando para uma capacidade plástica e pegajosa. Estas transições são conhecidas como limites de Atterberg, que os codificou em 1912. Esses limites críticos variam em função da umidade, da textura, do tipo e quantidade de argilominerais, da estrutura, do teor de matéria orgânica e cátions trocáveis.

Consistência refere-se, portanto à propriedade dinâmica dos solos em manifestar sua resistência em mudar sua forma, sob várias condições de umidade. $O$ termo consistência refere-se ao grau de adesão entre as partículas de solo e à resistência oferecida a forças que tendam a deformar ou romper a massa do solo. É a influência que as forças de coesão e adesão exercem sobre os constituintes do solo, variando de acordo com a umidade. Sendo a consistência a manifestação das forças de coesão e adesão no solo, a primeira é máxima em solo seco e a segunda em solo úmido. Estas manifestações são influenciadas pelo teor de umidade e argila. Propriedades do solo como resistência à ruptura ou tenacidade, facilidade de esborroamento ou friabilidade, plasticidade, aderência ou pegajosidade, são exemplos de consistência.

O limite de contração refere-se a umidade que determina o limite inferior da zona de friabilidade do solo. Constitui-se, portanto, num dos limites de consistência do solo. Para sua determinação, a metodologia clássica utiliza mercúrio e esse metal pode acarretar efeitos adversos, tanto para o meio ambiente como para a saúde humana. Nesse sentido, o trabalho teve como objetivo testar um método alternativo, com o uso da pastilha parafinada para a determinação do limite de contração.

\section{DESCRIÇÃO GERAL DA ÁREA DE ESTUDO}

O município de Santa Maria-RS, no que se refere ao relevo, reflete a condição da sua posição situada numa área de transição geomorfológica entre os Planaltos e Chapadas da Bacia Sedimentar do Paraná e a Depressão Periférica Sul-riograndense. As atuações dos agentes erosivos morfogenéticos definiram as formas de relevo e estão associados à diversidade litoestrutural da área abrangida pelo município. Nesse contexto, 
da região central do estado do Rio Grande do Sul e da Depressão Periférica Sul-riograndense, é que está situada a área de estudo junto ao Distrito de Pains, no município de Santa Maria-RS.

A área em estudo foi, e ainda vem sendo utilizada para o plantio de cultivos convencionais ao longo de décadas. Apresenta aspectos da biota regional e está inserida no domínio dos Campos com Capões e Matas Galerias (Vieira, 1984). Nos setores onde os processos erosivos esculpiram colinas alongadas (coxilhas) sobre essas litologias paleozóicas da Bacia do Paraná, aparecem solos medianamente profundos como os Argissolos sobre colinas, com ocorrência ocasional de sulcos e ravinas constituindo canais incisivos que evoluem para a formação dos cursos fluviais, integrantes da bacia hidrográfica do rio Vacacaí-Mirim.

No que se refere ao clima, de acordo com a classificação de Köppen apud Ayoade (1986), a região apresenta domínio climático do tipo $\mathrm{Cfa}$, ou seja, temperado chuvoso e quente, onde se registram temperaturas entre $-3^{\circ} \mathrm{C}$ e $18^{\circ} \mathrm{C}$ nos meses mais frios e nos meses mais quentes temperaturas superiores a $22^{\circ} \mathrm{C}$, sem nenhuma estação seca.

As amostras foram retiradas de uma área que abrange litologias da Formação Santa Maria (Membro Alemoa) onde o relevo apresenta forma de modelado de dissecação. Partiu-se do pressuposto de que esse modelado está relacionado à natureza do material sedimentar (areia fina, silte, argilas de baixa a média plasticidade, argilas arenosas e argilas siltosas), que constituem o substrato litológico da área. $\mathrm{O}$ perfil de solo selecionado para a tomada das amostras utilizadas na realização dos ensaios, apresenta um substrato litológico constituído pela Formação Santa Maria (Membro Alemoa) com litologia predominante de arenitos finos, siltitos, lamitos, argilitos e folhelhos síltico-argilosos. Conforme Bortoluzzi (1974) e Silva (1977), o Membro Alemoa caracterizase por ser constituído por rochas sedimentares de textura maciça (sem orientação) de caráter argiloso a síltico (lamito com pequena ocorrência de concreções calcárias). Na tomada das amostras, considerouse uma topossequência de vertente constituída por um ARGISSOLO VERMELHO Distrófico arênico situado na área experimental do Departamento de Solos, no Campus da Universidade Federal de Santa Maria, no município de Santa Maria, RS.

A Figura 1 ilustra a localização da área de estudo, de onde foram coletadas as amostras utilizadas nos ensaios, em relação ao Município e área urbana de Santa Maria, RS.

\section{PROCEDIMENTOS METODOLÓGICOS}

Para realização do trabalho fez-se uso do método dedutivo por esse ser uma das formas que permite uma maior proximidade da realidade com a pesquisa ora realizada. Para atingir o objetivo proposto pelo trabalho, adotaram-se como escala de observação os horizontes diagnósticos do perfil de solo, a identificação e a caracterização do perfil de solo em trincheira seguindo-se um procedimento de reconhecimento geral do comportamento das vertentes da área experimental do Departamento de Solos no Campus da Universidade Federal de Santa Maria.

O perfil de solo foi descrito conforme as características morfológicas dos horizontes diagnósticos (Santos et al., 2005). As características morfológicas visualizadas possibilitaram a identificação dos horizontes diagnósticos. Nesse sentido, os horizontes diagnósticos descritos foram A, E e Bt. Desses horizontes diagnósticos, foram coletadas amostras deformadas. A Figura 2 mostra o perfil do solo e a Figura 3 ilustra o aspecto geral da paisagem da área. O Quadro 1 mostra a descrição morfológica dos horizontes diagnósticos do perfil amostrado.

Os ensaios foram realizados no Laboratório de Sedimentologia do Departamento de Geociências da Universidade Federal de Santa Maria. Os valores dos limites de contração foram obtidos a partir de oito repetições utilizando-se duas metodologias: o método MB-55 (ABNT, 1948) citado por EMBRAPA (1997) que utiliza o mercúrio metálico e, o método alternativo em estudo que utiliza a pastilha parafinada. A figura 4 ilustra os procedimentos utilizados. O procedimento entre os dois métodos é idêntico, diferindo, entretanto na forma de calcular o volume do corpo de prova seco. No método proposto pela MB-55 (ABNT, 1948), o volume do corpo de prova seco é determinado usando-se o volume de mercúrio transbordado. Já no método que utiliza a pastilha parafinada, o volume do corpo de prova seco (volume final) é determinado da seguinte forma: após a secagem do corpo de prova 


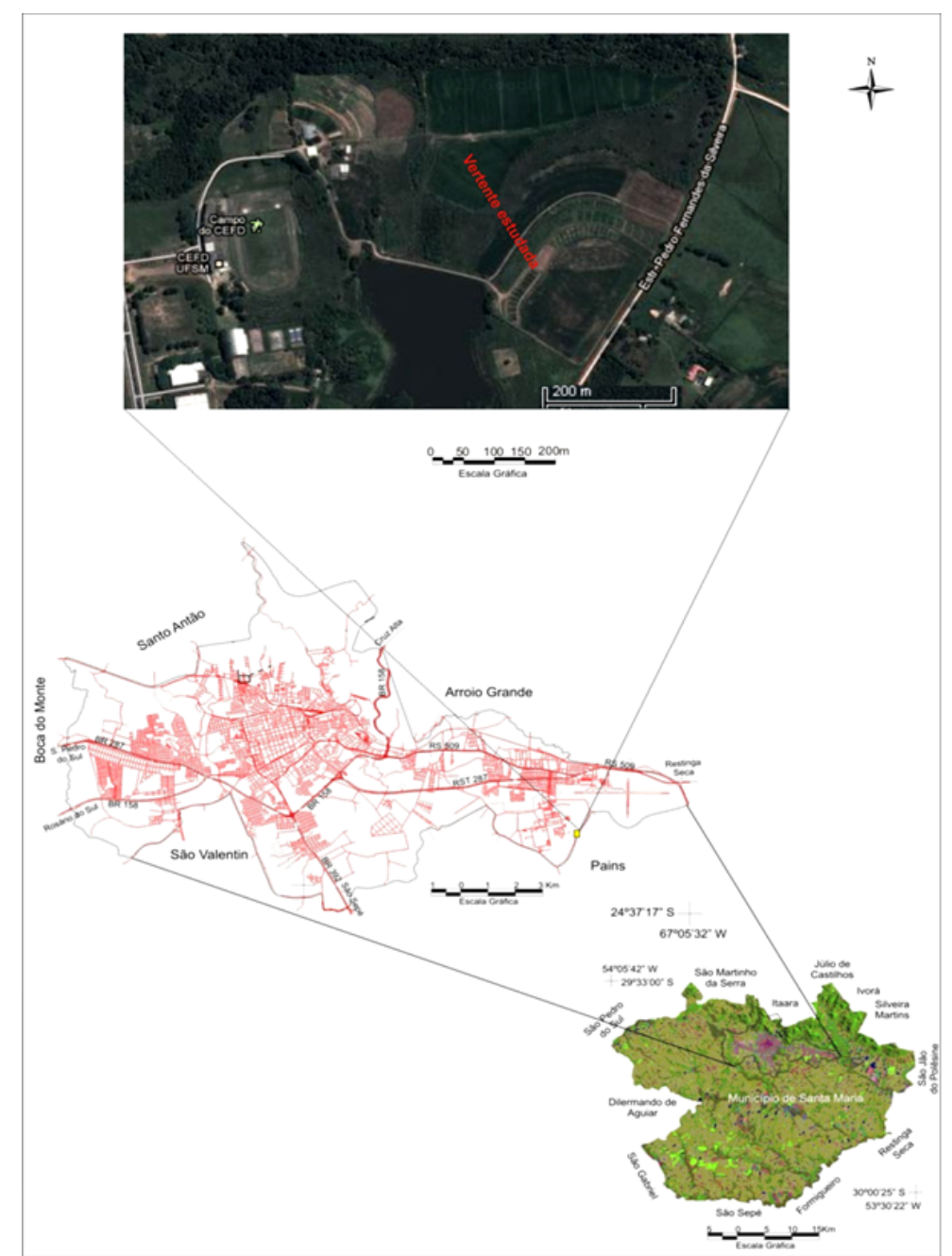

Figura 1: Localização, em relação ao município de Santa Maria, RS, da área da vertente do perfil de solo de onde foram retiradas as amostras.

Fonte: organizado pelos autores. Imagem aérea adaptada de: <http://maps.google.com.br/maps?hl=en\&tab=wl. Acesso: 09 jul. $2013>$.

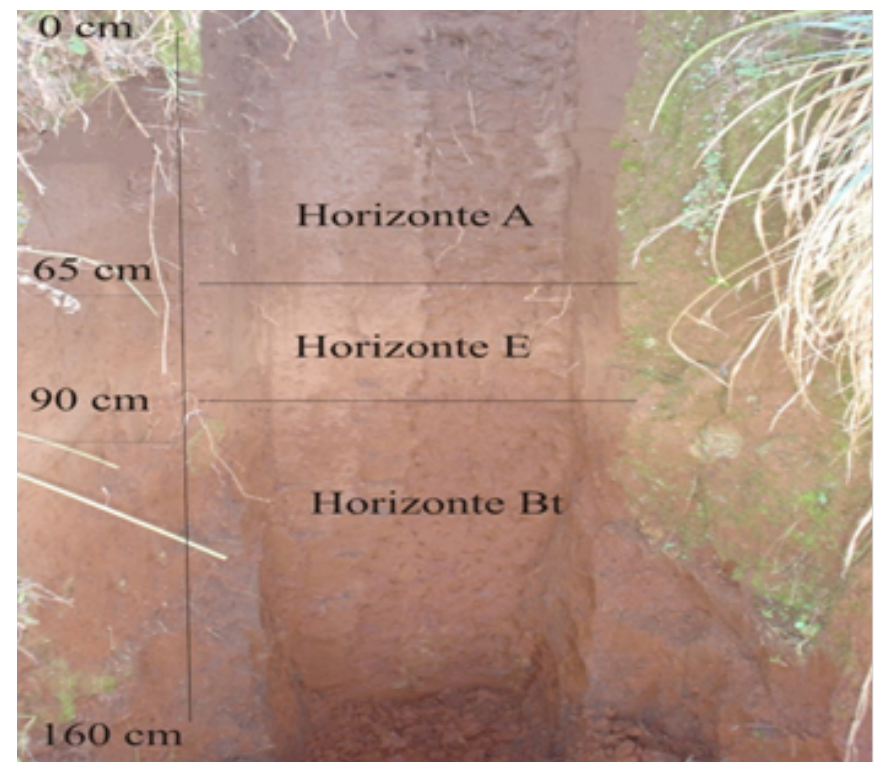

Figura 2: Perfil do solo de onde foram descritos os horizontes diagnósticos e retiradas as amostras para a realização dos ensaios. Fonte: acervo dos autores. 


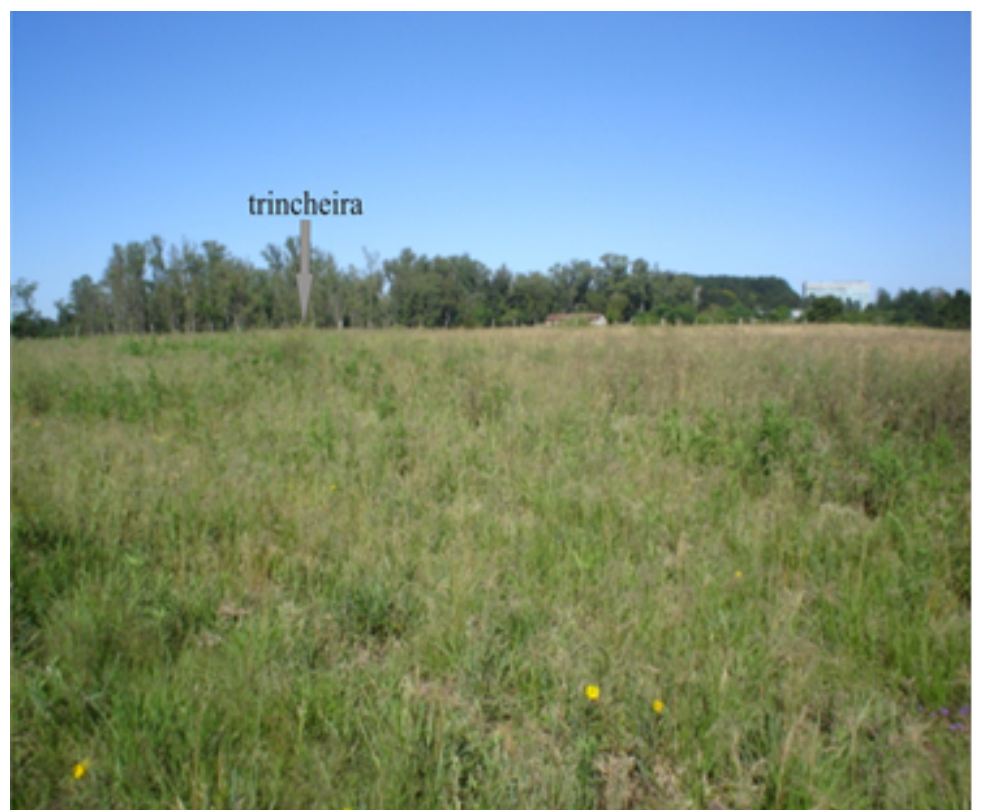

Figura 3: Aspecto geral da paisagem da área onde foi aberta a trincheira e coletadas as amostras de solo. Fonte: acervo dos autores.

Quadro 1: Descrição morfológica, conforme Lemos; Santos (1993), dos horizontes diagnósticos identificados no perfil de solo utilizado como unidade amostral.

DATA: 07/08/2012

LOCALIZAÇÃO: Campus da UFSM, área experimental do Departamento de Solos, afloramento/corte de estrada lado direito da estrada.

ALTITUDE: $95 \mathrm{~m}$

FORMAÇÃO GEOLÓGICA: Formação Santa Maria (Membro Alemoa).

MATERIAL ORIGINÁRIO: arenitos finos, siltitos, lamitos, argilitos e folhelhos sílticoargilosos.

RELEVO LOCAL: suave ondulado.

RELEVO REGIONAL: suave ondulado.

EROSÃO: laminar ligeira.

CLIMA: Cfa, mesotérmico brando na classificação de Köppen, Udic e Thermic.

DRENAGEM: bem drenado.

VEGETAÇÃO: Campo Subtropical Subúmido.

USO ATUAL: lavoura temporária e pastagem cultivada.

Horizonte A: 0-65 cm; bruno avermelhado escuro (5 YR 3/2, úmido); franco arenosa; fraca, pequena a média, blocos angulares e subangulares; poros comuns pequenos e médios; muito friável, ligeiramente plástica e ligeiramente pegajosa; transição plana e difusa; raízes comuns.

Horizonte E: $65-90 \mathrm{~cm}$; bruno avermelhado claro (5 YR 4/4, úmido); franco argilosa; fraca, pequena a média, blocos angulares e subangulares; poros muitos pequenos e médios; muito friável, ligeiramente plástica e ligeiramente pegajosa; transição plana e difusa; raízes poucas.

Horizonte Bt: $90+\mathrm{cm}$; vermelho (2,5 YR 4/8, úmido); argilosa; moderada a forte, pequena a média, blocos angulares e subangulares; cerosidade ausente; poros comuns, pequenos e médios; firme, ligeiramente plástica e ligeiramente pegajosa; transição plana e difusa; raízes raras.

Obs: Presença de concreções a $155 \mathrm{~cm}$ numa espessura de $8 \mathrm{~cm}$.

Fonte: elaborado pelos autores. 
em estufa a $105-110^{\circ} \mathrm{C}$ durante 24 horas, ele é amarrado com um fio de arame, pesando-o para a obtenção do seu peso seco ao ar, a seguir, o corpo de prova é introduzido várias vezes em um banho de parafina a $60^{\circ} \mathrm{C}$, até o seu recobrimento total (EMBRAPA, 1997). O corpo de prova parafinado ao ar é pesado e, a seguir imerso em água destilada e obtém-se o volume do corpo de prova mais a parafina, pela expressão sugerida por Gandolfi et al., (1980); o volume do corpo de prova mais a parafina é igual ao peso do corpo de prova parafinado ao ar menos o peso do corpo de prova parafinado imerso em água, dividindo-se este resultado pelo valor da densidade da água destilada. O volume da parafina é calculado pela expressão: volume da parafina é igual ao peso do corpo de prova parafinado ao ar menos o peso do corpo de prova sem a parafina ao ar, dividindo-se este resultado pelo valor da densidade da parafina. Por fim, o volume final do corpo seco será igual á diferença entre o volume do corpo de prova mais a parafina e o volume da parafina.

A obtenção do cálculo do limite de contração foi a partir da seguinte expressão (STANCATI; NOGUEIRA; VILAR, 1981):

$$
U c=U m-\frac{(V o-V f) \partial a}{M s}
$$

Onde:

$U c=$ limite de contração (\%);

Um = umidade de moldagem (\%);

Vo = volume inicial do corpo de prova, igual ao volume do molde (cm3);

$V f=$ volume final do corpo de prova (cm3);

$M s=$ massa do corpo de prova seco $(g)$;

$\partial a=$ densidade da água $(\mathrm{g} \mathrm{cm}-3)$.

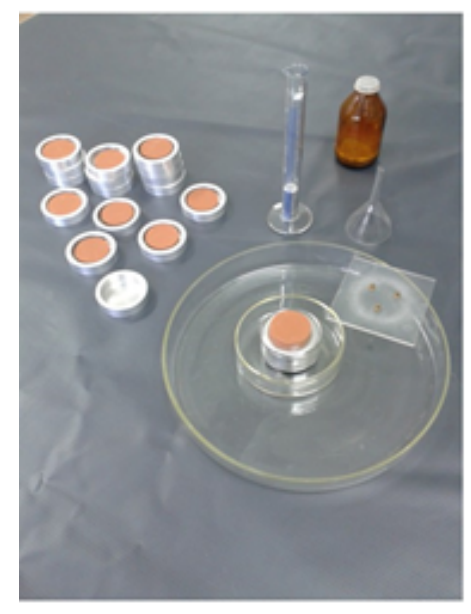

A

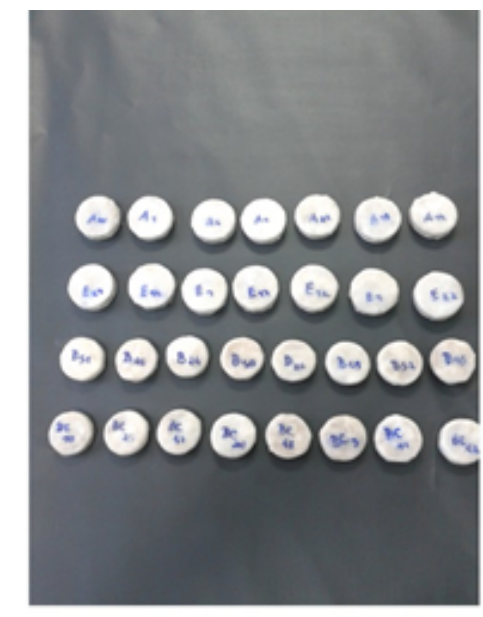

B

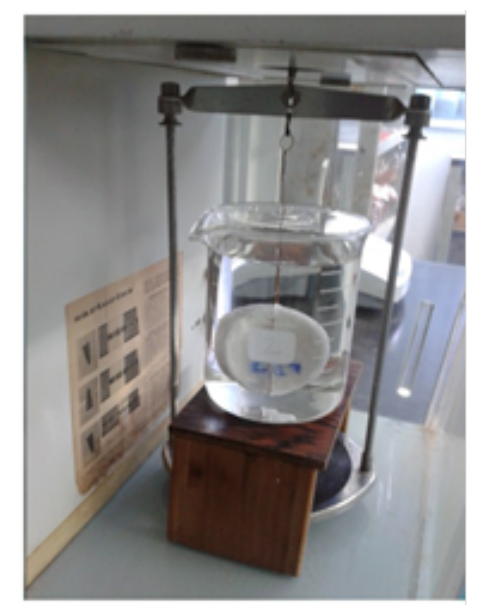

C

Figura 4: llustração dos procedimentos entre os dois métodos empregados para determinação do limite de contração. Em $A$, está ilustrado o procedimento com o uso de mercúrio metálico, em B, estão as pastilhas parafinadas e, em C, está ilustrado o corpo de prova parafinado ao ar sendo pesado imerso em água destilada.

Fonte: acervo dos autores. 
Tabela 1: Método do mercúrio: valores obtidos para a determinação do limite de contração (LC) - Horizonte A.

\begin{tabular}{|c|c|c|c|c|c|c|c|c|}
\hline Amostra ( $n^{0}$ cápsula) & 2 & 4 & 1 & 6 & 19 & 18 & 21 & 40 \\
\hline Amostra úmida + cápsula & 54,166 & 53,971 & 56,602 & 52,647 & 53,549 & 53,545 & 52,860 & 52,81 \\
\hline Amostra seca + cápsula & 49,524 & 49,227 & 52,069 & 48,03 & 48,754 & 48,759 & 48,230 & 48,153 \\
\hline Peso cápsula & 29,792 & 28,977 & 32,591 & 28,511 & 28,418 & 28,485 & 28,476 & 28,485 \\
\hline Pesoágua & 4,642 & 4,744 & 4,533 & 4,617 & 4,795 & 4,786 & 4,630 & 4,657 \\
\hline Peso amostra seca & 19,732 & 20,250 & 19,478 & 19,519 & 20,336 & 20,274 & 19,754 & 19,668 \\
\hline$\%$ umidade & 23,53 & 23,43 & 23,27 & 23,65 & 23,58 & 23,61 & 23,44 & 23,68 \\
\hline Volume cápsula (V) & 12,4 & 12,4 & 12,2 & 12,4 & 12,4 & 12,4 & 12,4 & 12,4 \\
\hline Volume solo seco(Vo) & 11,2 & 11,2 & 11 & 11,2 & 11,2 & 11,2 & 11,2 & 11,2 \\
\hline Volume contraído (V-Vo) & 1,2 & 1,2 & 1,2 & 1,2 & 1,2 & 1,2 & 1,2 & 1,2 \\
\hline Área contraída $(A)$ & 6,08 & 5,93 & 6,16 & 6,15 & 5,90 & 5,92 & 6,07 & 6,10 \\
\hline Limite contração & 17,44 & 17,50 & 17,11 & 17,51 & 17,68 & 17,69 & 17,36 & 17,58 \\
\hline Razão Contração & 1,76 & 1,81 & 1,77 & 1,74 & 1,82 & 1,81 & 1,76 & 1,76 \\
\hline
\end{tabular}

Tabela 2: Método da pastilha parafina: valores obtidos para a determinação do limite de contração (LC) - Horizonte A.

\begin{tabular}{|c|c|c|c|c|c|c|c|c|}
\hline Amostra ( $n^{0}$ cápsula) & 2 & 4 & 1 & 6 & 19 & 18 & 21 & 40 \\
\hline Ms & 19,7365 & 20,2691 & 19,4537 & 19,5116 & 20,3637 & 20,2755 & 19,7567 & 19,6667 \\
\hline$M s p$ & 24,8151 & 25,1914 & 24,4151 & 24,0745 & 24,7967 & 24,5696 & 24,2851 & 23,7911 \\
\hline Mbsp + peso arame & 8,2163 & 8,5798 & 8,4116 & 8,2226 & 8,7383 & 8,8833 & 8,6785 & 8,3404 \\
\hline Peso arame & 0,0812 & 0,0830 & 0,2451 & 0,0889 & 0,2505 & 0,2466 & 0,2237 & 0,0795 \\
\hline Mbsp & 8,1351 & 8,4968 & 8,1665 & 8,1337 & 8,4878 & 8,6367 & 8,4548 & 8,2609 \\
\hline$M p$ & 5,0796 & 4,9223 & 4,9614 & 4,5629 & 4,433 & 4,2941 & 4,5284 & 4,1244 \\
\hline Volume solo seco $(\mathrm{Vo})^{*}$ & 11,0 & 11,1 & 10,6 & 10,8 & 11,3 & 11,1 & 10,7 & 10,9 \\
\hline Limite contração & 16,20 & 17,13 & 15,24 & 15,34 & 18,13 & 17,06 & 14,86 & 15,85 \\
\hline Razão Contração & 1,80 & 1,82 & 1,83 & 1,81 & 1,80 & 1,83 & 1,85 & 1,81 \\
\hline
\end{tabular}

\section{Fonte: elaborado pelos autores.}

${ }^{*}$ Determinação Vo parafina $=(M s p-M b s p / P w)-(M p / P p)$ onde: $M s=$ massa da pastilha seca antes de ser parafinada; $M s p=m a s s a$ da $p a s-$ tilha seca parafinada; $M b s p=$ =eso imerso da pastilha coberta de parafina; $M p=$ massa da cobertura de parafina; $P w=d e n s i d a d e ~ a ́ g u a ~(1 g /$ $\left.\mathrm{cm}^{3}\right) ; P p=$ densidade parafina $\left(0,8872 \mathrm{~g} / \mathrm{cm}^{3}\right)$. ${ }^{*}$ Determinação densidade parafina $=P w \times(W 2 /(W 1+W 2-W 3))$ onde: $P w=$ densidade água $\left(1 \mathrm{~g} / \mathrm{cm}^{3}\right) ; W 1$ = Peso submerso arame + lastro de $10 \mathrm{~g}(9,1013 \mathrm{~g})$; W2 = Peso seco parafina $(2,3553 \mathrm{~g})$; W3 = Peso submerso arame + lastro + parafina $(8,8019 g)$.

Tabela 3: Método do mercúrio: valores obtidos para a determinação do limite de contração (LC) - Horizonte E.

\begin{tabular}{|c|c|c|c|c|c|c|c|c|}
\hline Amostra ( $n^{0}$ cápsula) & 5 & 7 & 14 & 17 & 27 & 12 & 9 & 22 \\
\hline Amostra úmida + cápsula & 55,226 & 54,832 & 54,187 & 54,389 & 54,299 & 54,203 & 54,266 & 54,951 \\
\hline Amostra seca + cápsula & 51,159 & 50,867 & 50,289 & 50,483 & 50,399 & 50,274 & 50,364 & 50,926 \\
\hline Peso cápsula & 28,486 & 28,502 & 28,513 & 28,478 & 28,478 & 28,122 & 28,431 & 28,513 \\
\hline Pesoágua & 4,067 & 3,965 & 3,898 & 3,906 & 3,900 & 3,929 & 3,902 & 4,025 \\
\hline Peso amostra seca & 22,673 & 22,365 & 21,776 & 22,005 & 21,921 & 22,152 & 21,933 & 22,413 \\
\hline$\%$ umidade & 17,94 & 17,73 & 17,90 & 17,75 & 17,79 & 17,74 & 17,79 & 17,96 \\
\hline Volume cápsula (V) & 12,4 & 12,4 & 12,4 & 12,4 & 12,4 & 12,4 & 12,4 & 12,4 \\
\hline Volume solo seco(Vo) & 12 & 11,8 & 11,8 & 11,8 & 11,6 & 11,8 & 11,6 & 12 \\
\hline Volume contraído (V-Vo) & 0,4 & 0,6 & 0,6 & 0,6 & 0,8 & 0,6 & 0,8 & 0,4 \\
\hline Área contraída $(A)$ & 1,76 & 2,68 & 2,76 & 2,73 & 3,65 & 2,71 & 3,65 & 1,78 \\
\hline Limite contração & 16,17 & 15,05 & 15,15 & 15,02 & 14,14 & 15,03 & 14,14 & 16,17 \\
\hline Razão Contração & 1,89 & 1,90 & 1,85 & 1,86 & 1,89 & 1,88 & 1,89 & 1,87 \\
\hline
\end{tabular}

Fonte: elaborado pelos autores. 
Tabela 4: Método da pastilha parafina: valores obtidos para a determinação do limite de contração (LC) - Horizonte E.

\begin{tabular}{lrrrrrrrr}
\hline Amostra ( $\boldsymbol{n}^{\circ}$ cápsula) & $\mathbf{5}$ & $\mathbf{7}$ & $\mathbf{1 4}$ & $\mathbf{1 7}$ & $\mathbf{2 7}$ & $\mathbf{1 2}$ & $\mathbf{9}$ & $\mathbf{2 2}$ \\
\hline Ms & 22,675 & 22,3665 & 21,7895 & 22,0397 & 21,9094 & 22,1506 & 21,9275 & 22,4187 \\
\hline Msp & 27,2277 & 26,7196 & 26,1949 & 26,7349 & 25,9147 & 27,238 & 26,7338 & 27,5706 \\
\hline Mbsp + peso arame & 10,2182 & 10,4021 & 9,7931 & 10,0920 & 10,1713 & 10,2407 & 10,1415 & 10,0958 \\
\hline Peso arame & 0,0916 & 0,0850 & 0,0861 & 0,0828 & 0,0831 & 0,2335 & 0,2259 & 0,0927 \\
\hline Mbsp & 10,1266 & 10,3171 & 9,7070 & 10,0092 & 10,0882 & 10,0072 & 9,9156 & 10,0031 \\
\hline Mp & 4,5527 & 4,3531 & 4,4054 & 4,6952 & 4,0053 & 5,0874 & 4,8063 & 5,1519 \\
\hline Volumesoloseco(Vo) ${ }^{*}$ & 12,0 & 11,5 & 11,5 & 11,4 & 11,3 & 11,5 & 11,4 & 11,7 \\
\hline Limite contração & 16,04 & 13,58 & 13,76 & 13,25 & 12,72 & 13,55 & 13,13 & 15,00 \\
\hline Razão Contração & 1,89 & 1,95 & 1,89 & 1,93 & 1,94 & 1,93 & 1,93 & 1,91 \\
\hline
\end{tabular}

Fonte: elaborado pelos autores.

${ }^{*}$ Determinação Vo parafina $=(M s p-M b s p / P w)-(M p / P p)$ onde: $M s=$ massa da pastilha seca antes de ser parafinada; $M s p=m a s s a$ da pastilha seca parafinada; $M b s p=$ eso imerso da pastilha coberta de parafina; $M p=$ massa da cobertura de parafina; $P w=d e n s i d a d e$ água (1g/ $\left.\mathrm{cm}^{3}\right) ; P p=d e n s i d a d e$ parafina $\left(0,8872 \mathrm{~g} / \mathrm{cm}^{3}\right) .{ }^{*}$ Determinação densidade parafina $=P w \times(W 2 /(W 1+W 2-W 3))$ onde: Pw $=$ densidade água $\left(1 \mathrm{~g} / \mathrm{cm}^{3}\right) ; W 1=$ Peso submerso arame + lastro de $10 \mathrm{~g}(9,1013 \mathrm{~g}) ;$ W2 = Peso seco parafina $(2,3553 \mathrm{~g}) ;$ W3 = Peso submerso arame + lastro + parafina $(8,8019 \mathrm{~g})$.

Tabela 5: Método do mercúrio: valores obtidos para a determinação do limite de contração (LC) - Horizonte Bt.

\begin{tabular}{lrrrrrrrr}
\hline \multicolumn{1}{c}{ Amostra (n' cápsula) } & $\mathbf{2 0}$ & \multicolumn{1}{c}{$\mathbf{1 1}$} & $\mathbf{4 2}$ & $\mathbf{2 5}$ & $\mathbf{4 7}$ & \multicolumn{1}{c}{$\mathbf{4 8}$} & \multicolumn{1}{c}{3} & $\mathbf{1 0}$ \\
\hline Amostra úmida + cápsula & 50,298 & 50,521 & 50,152 & 50,222 & 49,815 & 50,482 & 50,055 & 50,329 \\
\hline Amostra seca + cápsula & 43,167 & 43,508 & 43,238 & 43,304 & 43,005 & 43,477 & 43,18 & 43,392 \\
\hline Peso cápsula & 28,495 & 28,466 & 28,480 & 28,490 & 28,488 & 28,478 & 28,376 & 28,516 \\
\hline Peso água & 7,131 & 7,013 & 6,914 & 6,918 & 6,810 & 7,005 & 6,875 & 6,937 \\
\hline Peso amostra seca & 14,672 & 15,042 & 14,758 & 14,814 & 14,517 & 14,999 & 14,804 & 14,876 \\
\hline \% umidade & 48,60 & 46,62 & 46,85 & 46,70 & 46,91 & 46,70 & 46,44 & 46,63 \\
\hline Volume cápsula(V) & 12,4 & 12,4 & 12,4 & 12,4 & 12,4 & 12,4 & 12,4 & 12,4 \\
\hline Volume soloseco(Vo) & 8,2 & 8,2 & 8,2 & 8 & 8,2 & 8,2 & 8,2 & 8,2 \\
\hline Volume contraído(V-Vo) & 4,2 & 4,2 & 4,2 & 4,4 & 4,2 & 4,2 & 4,2 & 4,2 \\
\hline Area contraída(A) & 28,63 & 27,92 & 28,46 & 29,70 & 28,93 & 28,00 & 28,37 & 28,23 \\
\hline Limite contração & 19,98 & 18,70 & 18,39 & 17,00 & 17,98 & 18,70 & 18,07 & 18,40 \\
\hline Razão Contração & 1,79 & 1,83 & 1,80 & 1,85 & 1,77 & 1,83 & 1,81 & 1,81 \\
\hline
\end{tabular}

Tabela 6: Método da pastilha parafina: valores obtidos para a determinação do limite de contração (LC) - Horizonte Bt.

\begin{tabular}{lcccccccc}
\hline Amostra ( $\mathbf{n}^{0}$ cápsula) & $\mathbf{2 0}$ & $\mathbf{1 1}$ & $\mathbf{4 2}$ & $\mathbf{2 5}$ & $\mathbf{4 7}$ & $\mathbf{4 8}$ & $\mathbf{3}$ & $\mathbf{1 0}$ \\
\hline$M s$ & 14,6741 & 14,6683 & 14,8369 & 14,4838 & 14,8104 & 14,4215 & 14,3689 & 14,4934 \\
\hline Msp & 19,5737 & 20,5220 & 18,9970 & 18,9483 & 18,4795 & 18,3209 & 18,7552 & 17,4551 \\
\hline Mbsp+ peso arame & 6,4206 & 6,2705 & 6,7153 & 6,2705 & 6,6164 & 6,5342 & 6,5035 & 6,6255 \\
\hline Peso arame & 0,0788 & 0,2578 & 0,2313 & 0,0837 & 0,2228 & 0,229 & 0,242 & 0,2322 \\
\hline Mbsp & 6,3418 & 6,0127 & 6,4840 & 6,1868 & 6,3936 & 6,3052 & 6,2615 & 6,3933 \\
\hline$M p$ & 4,8986 & 5,8537 & 4,1601 & 4,4645 & 3,6691 & 3,8994 & 4,3863 & 2,9617 \\
\hline Volume soloseco(Vo) & 7,7 & 7,9 & 7,8 & 7,7 & 7,9 & 7,6 & 7,5 & 7,7 \\
\hline Limite contração & 16,63 & 16,66 & 15,73 & 15,06 & 16,15 & 14,73 & 13,56 & 15,09 \\
\hline Razão Contração & 1,90 & 1,91 & 1,89 & 1,92 & 1,83 & 1,97 & 1,97 & 1,93 \\
\hline
\end{tabular}

${ }^{*}$ Determinação Vo parafina $=(M s p-M b s p / P w)-(M p / P p)$ onde: $M s=$ massa da pastilha seca antes de ser parafinada; $M s p=m a s s a$ da pas -

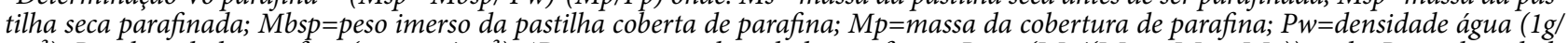
$\left.\mathrm{cm}^{3}\right) ; P p=$ densidade parafina $\left(0,8872 \mathrm{~g} / \mathrm{cm}^{3}\right)$. ${ }^{*}$ Determinação densidade parafina $=P w \times(W 2 /(W 1+W 2-W 3))$ onde: Pw $=$ densidade água $\left(1 \mathrm{~g} / \mathrm{cm}^{3}\right) ; W 1$ = Peso submerso arame + lastro de $10 \mathrm{~g}(9,1013 \mathrm{~g}) ;$ W2 = Peso seco parafina $(2,3553 \mathrm{~g})$; W3 = Peso submerso arame + lastro + parafina $(8,8019 g)$. 
Tabela 7 - Resultados do desvio-padrão e teste de significância para os valores do limite de contração (LC).

\begin{tabular}{|c|c|c|c|c|c|c|}
\hline $\mathrm{Hz}$ & $\begin{array}{c}\text { Média } \\
\text { LC Mercúrio }\end{array}$ & $\begin{array}{l}\text { Desvio-padrão } \\
\text { LC Mercúrio }\end{array}$ & $\begin{array}{c}\text { Média } \\
\text { LC Parafina }\end{array}$ & $\begin{array}{c}\text { Desvio-padrão } \\
\text { LC Parafina }\end{array}$ & $\begin{array}{c}\text { Teste t } \\
\text { (Student) }\end{array}$ & $\begin{array}{c}\text { Valor-p } \\
0,20 \\
\end{array}$ \\
\hline $\bar{A}$ & 17,48 & 0,19 & 16,83 & 1,13 & 1,600 & \\
\hline $\bar{E}$ & 15,11 & 0,77 & 13,88 & 1,10 & 2,544 & 1,533 \\
\hline$\overline{B t}$ & 18,40 & 0,84 & 15,45 & 1,06 & 6,053 & \\
\hline
\end{tabular}

\section{CONCLUSÃO}

Ao testar a substituição do mercúrio metálico (MB-55 ABNT, 1948) pela parafina na determinação do volume final do corpo de prova seco, o método da pastilha parafinada mostrou-se eficiente na determinação do limite de contração para os horizontes diagnósticos avaliados a um valor-p de 0,20 . Nesse sentido, conclui-se que a parafina pode substituir o mercúrio na determinação do volume final do corpo de prova seco nesse nível de significância. Para um nível de significância acima de $10 \%$ as médias diferem.

\section{REFERÊNCIAS BIBLIOGRÁFICAS}

ABRAHÃO, W. A. P., COSTA, L. M., MELLO, J. W. V.; NEVES, J.C. L. Distribuição de freqüência de tamanho da fração areia e compacidade relativa de solos desenvolvidos de sedimentos do grupo geológico Barreiras. Revista Brasileira de Ciencia do Solo. v. 22, p.1-9,1998.

AYOADE, J. Introdução a climatologia dos trópicos. São Paulo-SP: Difel, 1986.

ASSOCIAÇÃO BRASILEIRA DE NORMAS TÉCNICAS. Determinação do limite de contração e relação de contração de solos: método brasileiro, MB-55. Rio de Janeiro, 1948. $2 \mathrm{p}$.

BAVER, L. D., GARDNER, W. H., GARDNER, W. R. Física de Suelos. Union Tipografica Editorial Hispano-Americana. 4 Ed. México, 1972.

BORTOLUZZI, C. A. Contribuição à Geologia da Região de Santa Maria, Rio Grande do Sul, Brasil. Pesquisas, Porto Alegre, v.4, n.1, p.7 86, 1974.

EMBRAPA - Empresa Brasileira de Pesquisa Agropecuária. Manual de Métodos de Análise de Solo. 2 ed. Rio de Janeiro: EMBRAPA-CNPS, 1997.
GANDOLFI, N.; PARAGUASSU, A.B.; RODRIGUES, J.E.; MARINO, L.; MATTIELLO, F. Ensaios de laboratório em geologia. São Carlos: Universidade de São Paulo. Escola de Engenharia de São Carlos, Departamento de Geociências, 1980.

SANTOS, Raphael David dos; LEMOS, Raimundo costa de; SANTOS, Humberto Costa de; KER, João Carlos; ANJOS, Lúcia Helena Cunha dos. Manual de descrição e coleta de solos no campo. 5 ed.revisada e ampliada.Viçosa.Sociedade Brasileira de Ciência do Solo, 2005

SILVA, A. P.; KAY, B. D.; PERFECT, E. Factors influencing bulk density, reference bulk density and relative bilk density of soils. In: CONGRESSO LATINO AMERICANO DE CIÊNCIA DO SOLO, 23., Águas de Lindóia, 1996. Resumos Expandidos. Campinas, Sociedade Brasileira de Ciência do Solo, 1996.

SILVA, J. L. S. da. Estudo dos processos de silicificação e calcificação em rochas sedimentares mesozóicas do Rio Grande do Sul, Brasil. Tese de Doutorado (Programa de Pós Graduação em Geociências), Universidade Federal do Rio Grande do Sul, Porto Alegre,1997.

STANCATI, G.; NOGUEIRA, J. B.; VILAR, O. M. Ensaios de laboratório em mecânica do solo. São Paulo: Escola de Engenharia de São Carlos, Departamento de Geotecnia, 1981.

VIEIRA, E.F. Rio Grande do Sul. Geografia física e vegetação. Porto Alegre-RS: Sagra, 1984.

Correspondência dos autores:

Rômulo Augusto Aragones Aita e-mail: romuloaita@gmail.com 
Ronaldo Facco
e-mail: ronaldo-facco@bol.com.br
Arthur Piccolo Werlang
e-mail: werlang.a@gmail.com
Mauro Kumpfer Werlang
e-mail: mkwerlang@smail.ufsm.br

Artigo recebido em: 29/09/2014

Aceito para publicação em: 08/10/2015 